\title{
Occupational Stress and Associated Factors among Nurses working in Public Hospitals of Arsi Zone, Oromia Regional State, Central Ethiopia, 2018
}

\author{
Biniam Worku Hailu, Yohannes Ejigu, Yibeltal Siraneh \\ Department of Health Economics, Management and Policy, Jimma University, Jimma, Ethiopia \\ Email address: \\ Biniamworku50@gmail.com (B. W. Hailu)
}

\section{To cite this article:}

Biniam Worku Hailu, Yohannes Ejigu, Yibeltal Siraneh. Occupational Stress and Associated Factors among Nurses working in Public Hospitals of Arsi Zone, Oromia Regional State, Central Ethiopia, 2018. International Journal of Biomedical Engineering and Clinical Science. Vol. 6, No. 2, 2019, pp. 17-28. doi: 10.11648/j.ijbecs.20200602.11

Received: September 16, 2019; Accepted: October 22, 2019; Published: April 30, 2020

\begin{abstract}
Nursing, by its nature, is an occupation subject to a high degree of stress. This profession involves working with people who are themselves suffering a considerable degree of stress. Occupational stress compromised quality of service delivery and also leads as employees' burnout, turnover and absenteeism. The Objective of the study is to determine the level of occupational stress and associated factors among nurses. The study employed facility based cross sectional study was conducted from August 13 -September 02, 2018. All nurses who served at least for 6 months in Arsi zone public hospitals were asked using self-administered structured questionnaire. The collected data was checked manually, edited, coded and entered into Epi-data version 3.1 and finally it was exported in to statistical package for social science version 24 for cleaning and analysis. Descriptive statistics were used to estimate frequency percent and mean. Dependent variables (occupational stress) were computed based on the respondents having average score of mean and above in expanded nursing stress scale. Then, associations between independent and dependent variables were analyzed first using bivariate binary logistic regression. Variables that had $\mathrm{p}<0.25$ on bivariate binary logistic regression were entered into multivariable binary logistic regression and adjusted odds ratio (AOR) with 95\% CI were reported. The study finding showed that 202 (53\%) with (95\% CI: 48.2-58.1) of nurses were occupationally stressful. Factors significantly associated with occupational stress among nurses were sex of respondents (female: $\mathrm{AOR}=2.37,95 \% \mathrm{CI}$ : 1.41, 3.97), marital status (ever married: $\mathrm{AOR}=2.49,95 \% \mathrm{CI}$ : 1.35, 4.60), Role ambiguity (nurses who had Role ambiguity: $\mathrm{AOR}=3.01,95 \% \mathrm{CI}: 1.79,5.05$ ) and working hours. ( $\geq 8 \mathrm{hrs}$ hours per day: $\mathrm{AOR}=2.85,95 \% \mathrm{CI}: 1.10,7.36$ ). In this study, more than half of nurses had occupational stress, Thus, Arsi zone public hospitals collaborative with concerned stakeholders to design stress reduction program for tackling occupational stress among nurses.
\end{abstract}

Keywords: Occupational Stress, Nurses, Associated Factors

\section{Introduction}

The National Institute for Occupational Safety and Health (NIOSH) defines occupational stress as "the harmful physical and emotional responses that occur when the requirements of the job do not match the capabilities, resources, or needs of the worker [1]. Nurses play a pivotal role in any health care institution and encompass the largest workforce in any health care institution. Nurses are direct caregivers and caring is an interpersonal procedure defined by expert nursing, interpersonal sensitivity and intimate relationships, including positive communication and implementation of professional knowledge and skills. Sometimes nurses are required to serve for a long period of time without having adequate rest $[2,3]$. As a result, nursing occupation is subject to a high degree of stress. Moreover, the profession involves working with people who are themselves suffering a considerable degree of stress. Sometimes patients can be difficult, frightened and angry. and nurses can find themselves responding with a growing 
sense of irritability and frustration, which may lead to quitting the profession $[4,5]$.

According to the Health and Safety Executive organization 2010 report, stress has consistently been the second most commonly reported type of work-related illness in the world [6]. For instance, in the United Kingdom stress is responsible for the loss of $49 \%$ of total working days [7]. Although, people are increasingly accustomed with occupational stress and how to manage it, the problem have persisted and even seems to be increasing [6]. However, in some developing countries, people are not aware of the importance of dealing with occupational stress [5].

Occupational stress may affect significantly nurse's quality of life, and simultaneously reduce the quality of nursing care, and it also affects performance at work. It resulted in loss of compassion for patients and increased incidences of practice errors and therefore is unfavorably associated to quality of care. Numerous studies show that stress has a direct or indirect impact on the delivery of care and on patient results [8-13].

As to our knowledge, there is no study which assessed occupational stress and associated factors among nurses in Arsi zone public hospitals. Therefore, this study was assessed occupational stress and associated factors among nurses working in public Hospitals to fill the research gap.

\subsection{Statement of the Problem}

Globally, the costs of work-related stress are estimated to be approximately $\$ 5.4$ billion each year., second to the most frequent occupational health problem, low back pain, and estimated to affect one in three employees [6]. It is a global problem with an estimated $9.20 \%$ to $68.0 \%$ of nurses suffering from stress $[9,15]$. Problems start to occur when the stress response is inappropriate to the size of the challenge. If not managed, high stress levels result in high levels of employee dissatisfaction, illness, absenteeism, high turnover, decreased productivity, and as a result, difficulty in providing quality service to clients [10]. Additionally, it effect on efficiency and economic cost on employers and great impact on patients' care [2, 10].

In particular stress in the nursing profession has been a major worldwide problem according to studies conducted in different countries. A study among personnel of a United Kingdom health authority reported that nurses were under the greatest pressure among all health care personnel [7]. Typically, absence rates in health care sectors are rising worldwide. The problem of high turnover and absence in nursing is of great concern, because it leads to increasing pressure on the personnel not (yet) ill, and in turn, more illness and burnout due to increasing pressure. Moreover, stress related absenteeism and turnover are costly. National survey conducted in Europe estimated that almost $10 \%$ of the Gross National Product in European countries is lost because of stress related absenteeism and turnover [16, 17].

The study conducted in Indian revealed that [87.4\%] of Indian nurses reported stressed [18]. According to study conducted in Greater Accra Region in Ghana revealed that a cause of stress to nurses was number of working hours, financial difficulties, and death of patient [17].

Ethiopia has one of the lowest health workers per population ratio in African countries according to world health organization report indicated that one health worker served for every 4,050 population this Human resource crisis exists in Ethiopia due to resource constraints, macroeconomic and governing factors [19, 20]. But, according to health sector development programme (HSDP) IV final report in Ethiopian there was gap with regard to shortage of nursing staff nationally and nurse to population ratio nationally showed that 1: 3,870 [21]. Furthermore Oromia regional nurse to population ratio was 1:5,706 which indicates there was shortage of nurses within the region [21]. Besides this there are continuous complaints of nurses specially those who works in hospitals about work overload and there was research data which supports work overload brings occupational stress in Ethiopia [5].

The study conducted in Addis Abeba, Ethiopia revealed that $(37.8 \%)$ nurses reported experiencing occupational stress. Significant associations were found between nurses' stress and gender, work shift, illness, marital status, and worksite. Magnitude of occupational stress was higher than estimated [14]. Also study conducted in East Gojjam Zone Public Hospitals the study revealed that $57.3 \%$ of nurses were stressed. Workload was the most causes of stress followed by patient death and dying and uncertainty concerning treatment. Sex and work experience of respondents were significantly associated with occupational stress [5]. According to study conducted in Jimma Zonal hospital revealed that an average overall job related stress level of nurses was $58.46 \%$. The highest level of occupational stress was on the sub scale of dealing with death \& dying mean score of $62.94 \%$ followed by uncertainty regarding patient treatment $57.72 \%$ and workload 57.6\% [2].

Previously conducted studies in Ethiopia most of them were not clearly address all important areas of modified nursing stress scale like Dealing with abusive patients, Difficulty in working with a particular nurse and Unpredictable staffing/schedule besides this occupational stress among nurses were marginalized and cannot got attention ranged from hospital administrators to policy makers. Therefore, this study was conducted to estimate the magnitude of occupational stress and associated factors among nurses working public hospitals of Arsi Zone, Oromia regional state, Central Ethiopia.

\subsection{Significance of the Study}

Studies of the source, level and associated factors of occupational stress were conducted in different part of the world and also stress is a complex phenomenon which results from interaction between an individual and the environment factors that ends with poor quality of health service delivery, employees' burnout, turnover and absenteeism. [22-25].

Therefore, this study provide information for nurse 
professionals, hospitals administrators and health policy makers concerning the level and associated factors of occupational stress. The information generated will be useful in designing appropriate interventions to develop stress reduction strategies and program. Furthermore, this study will also generate knowledge that can contribute to ongoing research efforts and also will be used as additional input for further study in the same area of inquiry.

\subsection{Literature Review}

\subsubsection{Level of Occupational Stress Among Nurses}

According to Cross-sectional study in Isfahan, Iran on nurses the study revealed that $34.9 \%$ of nurses reported their job was very or extremely stressful [31]. It is consistent with cross sectional study conducted in selected hospitals of Udupi and Mangalore districts Karnataka, India. Majority of the subjects i.e. $60.38 \%$ experience low stress, $38.46 \%$ experience moderate stress and stress was high among $1.15 \%$ of the subjects [12]. Another study conducted on two tertiary hospitals Delhi revealed that majority of nurses $(87.4 \%)$ found their jobs stressful with $32.2 \%$ reporting severe or extreme stress. Similarly, in relation to stress in their daily life, $87.4 \%$ reported some stress while $28.7 \%(25 / 87)$ reported severe/extreme stress. However, there was not much difference in stress levels depending upon the type of hospital $(\mathrm{p}=0.54)$ [32].

The cohort study conducted in hospitals on nurses in Gaza-Palestine. Revealed that the most severe occupational stressors were: Not enough staff to adequately cover unit (mean=1.58), followed by Watching a patient suffer (mean=1.52) and Lack of drugs and equipment required for nursing care $($ mean=1.46). The least frequent item of perceived occupational stressors is Listening or talking to a patient about his/her approaching death. Also, it shows that the most severe occupational stressors item appears to be not enough staff to adequately cover the unit (mean=2.97) followed by lack of drugs and equipment required for nursing care (mean=2.88) and unpredictable staffing and scheduling (mean=2.66). The least item of perceived severe occupational stressor is criticism by a physician (mean=1.72) [33].

The study conducted Darul Ehsan, in Malaysia revealed that work overload is the prominent factor of occupational stress among nurses working in hospital [11]. This study results similar with the study conducted Al Ahsa, Saudi Arabia hospital [34]. Also the cross-sectional exploratory study was carried out selected government hospitals in Gombe state; Nigeria the study revealed that - a work load stressor sub-scale with an estimated mean stress level of 3.36. Workload stress occasioned by not enough staff to adequately cover the unit [35].

A cross-sectional exploratory study was carried out among bed side Nurses in five selected government hospitals in Gombe state, Nigeria the study revealed that death and dying the main factor stressors next to workload with mean stress level of death and dying was 2.78 [35].

The study in Sudan revealed that the mean score of overall occupational stress experienced by nurses was 1.88 with standard deviation of 0.50 [36]. Also another similar study conducted in Sudan the study revealed that. The analysis of stress domains revealed that nurses rated that death and dying situations as the most stressful $(\mathrm{M}=2.23 ; \mathrm{SD}=0.56)$, followed by workload $(\mathrm{M}=2.16 ; \mathrm{SD}=0.61)$ and problems with supervisors $(\mathrm{M}=2.07 ; \quad \mathrm{SD}=0.82)$. The mean of occupational stress perceived when dealing with patients and their families was $1.92 \pm 0.62$ and stress due to uncertainty concerning treatments was $1.92 \pm 0.68$ [36].

The study conducted in Addis Abeba, Ethiopia revealed that One hundred twenty-one $(37.8 \%) \quad(95 \%$ confidence interval: 34.3 to 39.1$)$ nurses experiencing occupational stress [14].

The study conducted in Jimma Zonal hospital revealed that an average overall job related stress level of nurses were $58.46 \pm 12.62$. The highest level of job related stress was on the sub scale of dealing with death $\&$ dying mean score of $62.94 \%$ followed by uncertainty regarding patient treatment $57.72 \%$ and workload $57.6 \%$. While job related stress from sexual harassment had the lowest mean score of $46.19 \%$ [2].

\subsubsection{Factors Associated with Occupational Stress Among Nurses}

i. Socio-Demographic Factors

The study conducted in selected hospitals of India significant association is also observed between stress and marital status, $(p=0.04)$ married subjects being more stressed than subjects who are single.[12]. Another study conducted Dammam, Eastern Saudi Arabia majority of nurses Workrelated stress is more common among married nurses $(85.5 \%, \mathrm{P}<0.05)$ [37].

Cross sectional study conducted in public hospitals of Khartoum state, Sudan revealed that the marital status was associated significantly to overall stress. $\mathrm{P}=0.001$ [36]. The study conducted in Addis Ababa public hospitals indicated that Widowed and divorced nurses were 10 times more likely to experience occupational stress than married nurses [14].

The Cohort study conducted among nurses in GazaPalestine revealed that Severity of occupational stressors was significantly associated with age, $(\mathrm{F}=3.283, \mathrm{p}=0.020)$ [9]. Whereas other cross sectional study conducted in Delhi, India have found that there was statistically significant between age and stress The mean age of nurses claiming that their jobs are extremely stressful was $33.71 \mathrm{yrs}$, whereas it was 28.73 yrs for those with stress free jobs. $(p=0.14)$ [38]. The descriptive study conducted in selected hospitals of Udupi and Mangalore districts Karnataka, India. The study revealed that there is no relationship between age and stress of nurses. The Spearman Rho calculated was 0.037 with $p$ value of 0.238 which was not significant at 0.05 level [12].

The study conducted in Addis Ababa public hospitals revealed that female Nurses were twice more likely to suffer from work-related stress than males [14]. This finding was consistent with study done in East Gojjam zone hospitals [14]. 
The Cohort study conducted among nurses in GazaPalestine revealed that nurses with more than 15 years of experience have around two thirds of the odds of being distressed compared with those who have less than 5 years of experience [9]. Another cross sectional study conducted in Egypt Alexandria hospital, the study revealed that nurses with 20 or more years of experience were statistically significant for stress $(p=.000)$ [39].

The study conducted in East Gojjam Zone Public Hospitals in Ethiopia the study revealed that experienced nurses were $74.1 \%$ less likely stressful than those nurses who have had less than 5 years' work experience and significantly associated with occupational stress and those nurses who have had greater than 10 work experience were $82.6 \%$ less likely stressful than those nurses who have had less than 5 years' work experience and significantly associated with occupational stress [5].

The Cohort study conducted among nurses in GazaPalestine revealed occupational stressors was significantly associated specialization and qualifications [9].

The study conducted in India revealed a significant association between stress and professional qualification. Stress is experienced more by the nurses who are qualified with General Nursing and Midwifery [12]. The descriptive survey design conducted in Central hospital, Benin City the study revealed that statistically significant relationship between the rank of nurses and the types of occupational stress experienced by nurses [10].

ii. Working place Factors

The study conducted in Greater Accra Region in Ghana study revealed that causes of stress Most to nurses was number of working hour's service, financial difficulties, and death of patient as greatest source of stress to nurses. The least factors of stress was revealed by the study as lack of control over the work of nurses [17]. The descriptive study conducted in India the study Revealed that there is significant association between stress and area of work the median stress score 37 of nurses working in special ward is experience higher degree of stress [12].

iii. Working Time Factors

The study conducted in Addis Ababa the study revealed that nurses who were worked in shift four times more stressed than from those who were worked in fixed [14].

As elaborated in this literature review chapter the studies result and the methodology that were used related to occupational stress among nurses description was made ranged from country level to Global level.

Generally, Occupational stress encompasses physical, social, and psychological factors (Dimension) those enumerated were measures occupational stress level among nurses in the hospital unit regarding to this studies merely a few studies incorporated those all main Dimensions in their studies. Others studies conducted were linked with other than occupational stress variable. This make difficult to know the level of occupational stress in hospital unit.

The main factors of occupational stress among nurses that described in this literature review chapter were: - Socio-
Demographic, Work place and working time factors

Therefore this study has incorporated the main dimensions of occupational stress among nurses in this single study and come up with the level and associated factors of occupational stress among nurses. The major objective of the study is to determine the level of occupational stress and associated factors among nurses working in Public Hospitals specifically, it is:

1. To determine the level of occupational stress among nurses working in public Hospitals of Arsi Zone.

2. To identify factors associated with occupational stress among nurses working in public Hospitals of Arsi Zone.

\section{Methods and Materials}

\subsection{Study Area and Period}

Arsi zone is one of 20 zone of oromia regional state of Ethiopia. The capital city of the zone is Asela which is located 172KM from Addis Ababa and $72 \mathrm{Km}$ from Adama at south. The zone is bordered the south by Bale, on the south west by west Arsi zone, on North west by East Shewa, and on the East by West Hararghe. The Arsi zone has 26 woredas within the zone there are 502 Health posts, 105 health centers and 6 Government Hospitals.

In Arsi Zone there are six public hospitals within the hospital there are totally 420 nurses:-Abomsa hospital (54), Robe Hospital (38), Balee Hospital (32), Gubisa Hospital (30), Bokoji Hospital (52) and Asela teaching referral hospital (214).

In Arsi zone public hospitals totally there are 420 Nurses. 113 Physicians, 48 druggist and pharmacists, 70 Druggist and lab technologists, 3 Radiographers, and 9 other health professionals totally in Arsi zones public hospitals there are 667 health professionals.

The study was conducted from August 13 -September 02, 2018 in all public hospitals found in Arsi zone, Oromia Regional state, Central Ethiopia.

\subsection{Study Design}

Facility based cross-sectional study was conducted.

\subsection{Population}

\subsubsection{Source Population}

The source population for this study was all nurses who are working in Arsi Zone Public hospitals, central Ethiopia.

\subsubsection{Study Population}

Individual nurse's working in Arsi Zone public hospitals for more than six months.

\subsection{Eligiblity Criteria}

\subsubsection{Inclusion Criteria}

All nurses who were qualified as diploma holder and above were included in the study.

\subsubsection{Exclusion Criteria}


1. All nurses who had a work experience of less than 6 months at the time of the study was excluded because these nurses had not faced the true situation of the hospital environment, and the first six month for newly employed nurses were considered as a trial period.

2. Nurses who were: free service workers at the time of data collection were excluded.

\subsection{Sample Size Determination and Sampling Technique}

All eligible nurses working in Arsi zone public hospitals which were 405 since, the numbers of eligible nurses working in six public hospitals were manageable for the study therefore; the investigators included all eligible nurses in the study.

\subsection{Study Variable}

\subsubsection{Dependent Variable}

Occupational stress.

\subsubsection{Independent Variables}

Socio-demographic factors

1. Age, Sex, Educational status, work experience in nursing, Marital status, Presence of children and salary

Workplace factors:

1. Type of ward/unit

2. Responsibility

3. Role ambiguity

Working Time factors:

1. Hours worked/day

2. Working shift

\subsection{Operational Definition}

1. Occupational stress:-defines as "the harmful physical and emotional responses that occur when the requirements of the job do not match the capabilities, resources, or needs of the worker". Stress experienced by the nurse related to psychological, physical and social factors Occupational stress was measured by a scale which has a total of 54 items, and sum score range minimum score of 54 and maximum of 216 . It is categorized based on the respondents having average score and above the mean score were classified as having occupational stress while those score below the mean were considered as not having occupational stress.

a) Psychological factors: refers to sources of stress which was measured by three variables: death and dying, inadequate motional preparation and uncertainty concerning treatment in Expanded Nursing Stress Scale [40].

b) Physical factor: refers to the source of stress which was measured workload of nurses in ENSS [40].

c) Social factors: it indicates that the sources of stress which was measured three variable: conflict with physician, problems with peers and problems with supervisors in ENSS [40].
2. Workplace factors: refers to factors related to the employee work place which was measured type of ward, responsibility and Role ambiguity

3. Working Time factors: refers to factors related to the employee working time which was measured hours worked and working shift.

\subsection{Method of Data Collection and Procedure}

\subsubsection{Instruments and Measurements}

Data was collected using self-administered structured questionnaire. The English version of data collection tool and Items of questionnaire adopted from expanded nursing stress scale which was developed by Gray-Toft and Anderson and Revised by Susan E. French, Rhonda Lenton, Vivienne Walters and John Eyles [40]. In the items of questionnaire a slight adjustment made and related into local context. The questionnaire consists three sections. Part one consists:Socio-demographic information, Part two working place and time information and Part three Modified Expanded Nursing Stress Scale is a tool used to measures the level and factors of occupational stress among nurses in hospital units. ENSS contained 57 items with nine subscales which help to measure job related stress among nurses. From those items the investigators were used 54 items of ENSS. The remaining items was not be used for this study because of the items related with discrimination so that it is not relevant in our country context.

Generally the ENSS questionnaire designed with a likertscale format the response option indicate that $(1=$ never stressful, $2=$ =slightly stressful, $3=$ moderately stressful, 4=very much stressful). The higher the score, the more the respondents agreed that the situation was stressful. The final total stress score of each nurse was ranged of between 54 216. Reliability of the instrument was established with an overall Cronbach's alpha score of 0.90 [40].

\subsubsection{Personnel}

Six diploma nurses working outside the study hospitals recruited and assigned one nurse for each hospital for data collection purpose. Additional three BSc holders with survey experience were recruited as supervisors.

\subsubsection{Data Collection Procedures}

Before the day to data collection the principal investigator was made the necessary official contact with the concerned bodies and set the date and time of data collection. On the day of data collection, the data collectors they provided warm greeting and explanation on the purpose and objective of the study Then, Self-administered structure questionnaire was distributed by giving the appropriate instruction and explanation to assist the respondents how to fill the questions.

\subsection{Data Processing and Analysis}

Prior to analysis the collected data was checked manually and coded and was entered into Epi-data version 3.1 and finally the data was export to SPSS version 24 for cleaning 
and analysis. Descriptive statistics (frequencies, percentages and mean) were calculated to summarize the sociodemographic, working place and time characteristics of participants.

The main outcome variable was occupational stress which is composite variable that was taken the aggregated mean stress level of ENSS. It was categorized based on mean and above and below the mean score of ENSS.

First, the level of occupational stress among nurses was estimated using simple descriptive summary statistics. The numbers of items of ENSS sum up together according to their respective subscale dimension then using the SPSS transform command cases eight subscale dimensions of ENSS was created after that the frequencies (\%) of independent study variables were summarized using numerical summary measures. Tables, graphs, pie chart and text were used to present the result of the analyzed data.

Then, associations between independent and dependent variables were analyzed first using bivariate binary logistic regression. Variables that had $\mathrm{p}<0.25$ on bivariate binary logistic regression were entered into a multivariable binary logistic regression, reporting AOR and 95\% CI and P-values $<0.05$ was considered statistically significant.

\subsection{Data Quality Management}

Intensive training were given for data collectors and supervisors for one day by the principal investigator about the objectives, tool, and process of Data collection and how to maintain confidentiality of study subject.

The questionnaire was prepared in English language and then translate in to Amharic and Afaan Oromo language then back to English by language expert person to ensure consistency, contextualization and pretesting. Before to the actual data collection, pre-testing was done on 5\%(20) of the total study appropriate subjects other than the selected Hospital and that have the same characteristics health facility that was Mojo Hospital.

During data collection period supervisors responsibility were checking whether the questionnaire correctly filled or not and also to make close supervision to data collectors and then the principal investigator was checked the collected data manually, edited and coded and was entered into Epi-data version 3.1.

The findings of this study will be disseminated to Jimma University, institute of health science and department of health economics, management and policy and also the document was communicated to Arsi Zonal Health department, Oromia Regional Health Bureau and respective selected hospitals research were done. Finally we will attempt to publishing on scientific journal.

\section{Results}

\subsection{Socio Demographic Characteristics of the Respondents}

A total of 405 nurses were given the self-administered questionnaire. Of these, 381 filled and returned the questionnaire which makes the response rate $94 \%$. Respondents were 193 (50.7\%) from asela teaching referral hospital, 47 (12.3\%) from Abomsa hospital, 48 (12.6\%) from Bokoji hospital, 33 (8.7\%) from Robe Dida hospital 29 (7.6\%) from Bale gesgar hospital and 31 (8.1\%) from Gubisa hospital

Table 1. Socio-demographic characteristics of respondents for the study of Occupational stress and associated factors among nurses working in public hospitals of Arsi zone; $2018(N=381)$.

\begin{tabular}{|c|c|c|c|}
\hline Variables & Categories & Frequency & Percent \\
\hline \multirow{2}{*}{ Sex } & Male & 209 & 54.9 \\
\hline & Female & 172 & 45.1 \\
\hline \multirow{3}{*}{ Age } & $<25$ years & 57 & 15 \\
\hline & $25-30$ years & 240 & 63 \\
\hline & $>30$ years & 84 & 22 \\
\hline \multirow{4}{*}{ Religion } & 1. Orthodox & 215 & 56.4 \\
\hline & 2. Muslim & 88 & 23.1 \\
\hline & 3. Protestant & 75 & 19.7 \\
\hline & 4. Other (specify)* & 3 & 0.8 \\
\hline \multirow{4}{*}{ Ethnicity } & 1. Oromo & 273 & 71.7 \\
\hline & 2. Amhara & 94 & 24.7 \\
\hline & 3. Guragey & 9 & 2.4 \\
\hline & 4. Others $* *$ & 5 & 1.3 \\
\hline \multirow{2}{*}{$\begin{array}{l}\text { Marital } \\
\text { status }\end{array}$} & Ever married $^{++}$ & 199 & 52.2 \\
\hline & Never Married & 182 & 47.8 \\
\hline \multirow{3}{*}{$\begin{array}{l}\text { Have } \\
\text { children }\end{array}$} & Yes & 124 & 32.5 \\
\hline & No & 257 & 67.5 \\
\hline & $<3137$ & 41 & 10.8 \\
\hline \multirow{3}{*}{ Salary } & $3138-3579$ & 44 & 11.5 \\
\hline & $3580-4080$ & 79 & 20.7 \\
\hline & $>4085$ & 217 & 57.0 \\
\hline \multirow{2}{*}{ Education } & 1. Diplomaholder & 112 & 29.4 \\
\hline & 2. Bachelor degree and above & 269 & 70.6 \\
\hline \multirow{3}{*}{ Experience } & $<5$ years & 267 & 70.1 \\
\hline & 5-10years & 85 & 22.3 \\
\hline & $>10$ years & 29 & 7.6 \\
\hline
\end{tabular}

*=wakefeta $* *=$ wolaita, tigrey $++=$ Married, widowed, divorced.

\subsection{Work Place and Time Related Characteristics}

Most of participants $336(88 \%)$ had less than or equal to eight hours working per day. Majority of participants 345 $(90.6 \%)$ reported working shift of them were fixed. Regarding to working unit most of respondents had been working in inpatient departments $310(81.4 \%)$. Nearly half of the respondents reported role ambiguity regarding their profession $173(45.5 \%)$. Only, $41(10.3 \%)$ respondents had extra responsibility in their working unit (Table 2).

Table 2. Frequency and mean score of response of nurse to Work place and time related characteristics, Arsi zone public hospitals, oromia regional state, Ethiopia, 2018.

\begin{tabular}{llll}
\hline Variables & Categories & Frequency & Percent \\
\hline \multirow{2}{*}{ Hour worked } & $\leq 8$ hours & 336 & 88 \\
& $>8$ hours & 45 & 12 \\
Work shift & Fixed & 345 & 90.6 \\
& Rotating & 36 & 9.4 \\
Department & Inpatient department & 310 & 81.4 \\
& Outpatient department & 71 & 18.6 \\
Role ambiguity & Yes & 173 & 45.5 \\
Extra & No & 208 & 54.5 \\
Responsibility & Yes & 41 & 10.3 \\
\hline
\end{tabular}




\subsection{Occupational Stress}

Occupational stress comprises three main factors: psychological, physical and social factors. A psychological factor includes death and dying, inadequate emotional preparation and uncertainty concerning treatment; Physical factor include workload and social factors includes conflict with physician, problems with peers, and problems with supervisors, patient and family.

\subsubsection{Psychological Factors}

Ninety $(23.6 \%)$ of respondents reported that patient death and fear of patient dying were very much stressful and only 3 $(0.8 \%)$ reported never stressful. the result shows that death and dying subscale has the highest mean score of 2.85 among psychological factors subscale (Table 3).

Table 3. Frequency and mean score of response of nurse to psychological factors of ENSS, Arsi zone public hospitals, oromia regional state, Ethiopia, 2018.

\begin{tabular}{|c|c|c|c|c|c|}
\hline \multirow[t]{2}{*}{ Subscales } & \multirow{2}{*}{$\begin{array}{l}\text { Never Stressful } \\
\text { N (\%) }\end{array}$} & \multirow{2}{*}{$\begin{array}{l}\text { Slightly } \\
\text { Stressful } \\
\mathbf{N}(\%)\end{array}$} & \multirow{2}{*}{$\begin{array}{l}\text { Moderately } \\
\text { Stressful } \\
\text { N (\%) }\end{array}$} & \multirow{2}{*}{$\begin{array}{l}\text { Very much } \\
\text { Stressful } \\
\mathbf{N}(\%)\end{array}$} & \multirow[t]{2}{*}{ Mean } \\
\hline & & & & & \\
\hline $\begin{array}{l}\text { Death and dying } \\
\text { Inadequate emotional preparation }\end{array}$ & $3(0.8)$ & $141(37)$ & $147(38.6)$ & $90(23.6)$ & 2.85 \\
\hline Inadequate emotional preparation & $28(7.3)$ & $181(47.5)$ & $144(37.8)$ & $28(7.3)$ & 2.45 \\
\hline Uncertainty concerning treatment & $25(6.6)$ & $145(38.1)$ & $145(38.1)$ & $66(17.3)$ & 2.66 \\
\hline
\end{tabular}

\subsubsection{Social Factors}

One hundred fifty two $(39.9 \%)$ of the participant reported that problems with supervisors were moderately stressful and only $28(7.3 \%)$ reported never stressful. The result shows that problems with supervisors subscale has the highest mean score of 2.45 among social factors subscale (Table 4).

Table 4. Frequency and mean score of response of nurse to Social factors of ENSS, Arsi zone public hospitals, Oromia regional state, Ethiopia, 2018.

\begin{tabular}{|c|c|c|c|c|c|}
\hline \multirow[t]{2}{*}{ Subscales } & Never Stressful & $\begin{array}{l}\text { Slightly } \\
\text { Stressful } \\
\end{array}$ & $\begin{array}{l}\text { Moderately } \\
\text { Stressful } \\
\end{array}$ & Very much Stressful & Mean \\
\hline & N (\%) & $\mathbf{N}(\%)$ & $\mathbf{N}(\%)$ & $\mathbf{N}(\%)$ & \\
\hline Conflict with physician & $57(15)$ & $177(46.5)$ & $130(34.1)$ & $17(4.5)$ & 2.28 \\
\hline Problems with peers & $41(10.8)$ & $197(51.7)$ & $126(33.1)$ & $17(4.5)$ & 2.31 \\
\hline Problems with supervisors & $34(8.9)$ & $167(43.8)$ & $152(39.9)$ & $28(7.3)$ & 2.45 \\
\hline Patient and their family & $44(11.5)$ & $192(50.4)$ & $131(34.4)$ & $14(3.7)$ & 2.3 \\
\hline
\end{tabular}

\subsubsection{Physical Factors}

Physical factors ENSS subscale had only workload subscale in this subscale the respondents reported 11 (2.9) were never stressful, 127 (33.6\%) were slightly stressful, 128 (33.6\%) were moderately stressful and 115 (33.6) very much stressful with the mean score of 2.9 (Table 5).

Table 5. Frequency and mean score of response of nurse to Physical factors of ENSS, Arsi zone public hospitals, oromia regional state, Ethiopia, 2018.

\begin{tabular}{llllll}
\hline \multirow{2}{*}{ Subscales } & Never Stressful & $\begin{array}{l}\text { Slightly } \\
\text { Stressful }\end{array}$ & $\begin{array}{l}\text { Moderately } \\
\text { Stressful }\end{array}$ & Very much Stressful \\
\cline { 2 - 5 } Mean \\
\cline { 2 - 5 } Workload & $\mathbf{N}(\%)$ & $\mathbf{N}(\%)$ & $\mathbf{N}(\%)$ & $\mathbf{N}(\%)$ & $115(33.6)$ \\
\hline
\end{tabular}

\subsection{Level of Occupational Stress Among Nurses}

Level of occupational stress was computed from the ENSS total score. Based on this $2(0.5 \%), 91(23.9 \%), 182(47.8 \%)$, $106(27.8 \%)$ were never, slightly, moderately and very much stressful respectively.

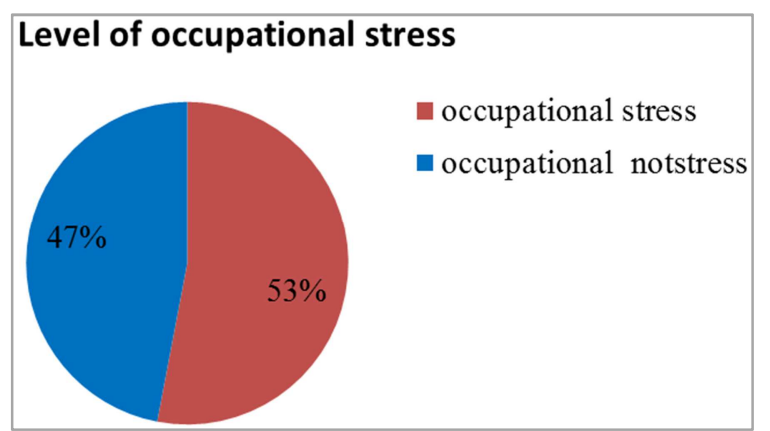

Figure 1. Level of occupational stress among nurses working in Arsi zone public hospitals, Ethiopia, 2018.
The ENSS of the sum score participants the reported that ranged from 54 to 207. where as the mean score of participants were 2.574 and above indicate occupational stress. from total of 381 nurse professionals 202 (53\%) nurse professionals score 2.574 and above on the ENSS Therefore the prevalence of occupational stress in this study was $53 \%$ (95\% CI: 48.2-58.1) (figure 1).

\subsection{Occupational Stress with Demographic Variables}

Concerning sex of respondent about 81 (38.8) of male respondents were stressful where as concerned with female respondents about $121(70.3 \%)$ were stressful. Regarding marital status about $131(72 \%)$ of ever married were stressful and $71(35.7 \%)$ of never married were stressful. Related with work experience of respondents from those nurses who had less than 5 year work experience about $121(45.3 \%)$ of study participants were stressful and about 146 (54.7) of study participants were not stressful the rest of variables refer to 
table below (Table 6).

Table 6. Occupational stress by demographic variables of nurses working in public Hospitals, of Arsi Zone Oromia, Ethiopia, 2018.

\begin{tabular}{lllll}
\hline \multirow{2}{*}{ Variables } & Category & \multicolumn{3}{l}{ Occupational stress } \\
\cline { 3 - 5 } & Male & Yes, N (\%) & Not, N (\%) & Total N (\%) \\
\hline \multirow{2}{*}{ Sex } & Female & $81(38.8)$ & $128(61.2)$ & $209(54.9)$ \\
& $<25$ years & $121(70.3)$ & $51(29.7)$ & $172(55.1)$ \\
Age & $26-30$ years & $35(61.4)$ & $22(38.6)$ & $57(15)$ \\
& $>30$ years & $109(45.4)$ & $131(54.6)$ & $24063)$ \\
Marital status & Never married & $58(69)$ & $26(31)$ & $84(22)$ \\
& Ever Married & $71(35.7)$ & $128(64.3)$ & $199(52.2)$ \\
Children & Yes & $131(72)$ & $51(28)$ & $182(47.8)$ \\
& No & $88(71)$ & $114(44.4)$ & $124(32.5)$ \\
Working Experience & $<5$ years & $36(29)$ & $143(55.6)$ & $257(67.5)$ \\
& $5-10$ years & $121(45.3)$ & $146(54.7)$ & $267(70)$ \\
Educational status & $>10$ years & $60(70.6)$ & $25(29.4)$ & $85(22.4)$ \\
& Diploma holder & $21(72.4)$ & $8(27.6)$ & $29(7.6)$ \\
Salary & Bachelor degree and above & $73(65.2)$ & $39(34.8)$ & $112(29.40)$ \\
& $<3137$ & $129(48.1)$ & $140(51.9)$ & $269(70.60)$ \\
& $3138-3579$ & $26(63.4)$ & $15(36.6)$ & $41(10.8)$ \\
& $3580-4080$ & $24(54.5)$ & $20(45.5)$ & $44(11.5)$ \\
& $>4085$ & $33(41.8)$ & $46(58.2)$ & $79(20.7)$ \\
\end{tabular}

\subsection{Occupational Stress with Working Time and Place Variables}

Concerning nurses who had worked more than eight hours per days 162 (48.5\%) of respondents were stressful where as concerned with nurses professionals who had worked less than eight hours per day about $40(85.1 \%)$ were stressful.
Regarding Nurse professional who had role ambiguity in their profession about $127(73.4 \%)$ of them were stressful and $46(26.6 \%)$ of nurse professionals didn't face role ambiguity were stressful the rest of variables refer to table below (Table 7).

Table 7. Occupational stress by working time and place variables of nurses working in public Hospitals, of Arsi Zone Oromia, Ethiopia, 2018.

\begin{tabular}{|c|c|c|c|c|}
\hline \multirow{2}{*}{ Variables } & \multirow{2}{*}{ Category } & \multicolumn{3}{|c|}{ Occupational stress } \\
\hline & & Yes, N (\%) & Not, N (\%) & Total N (\%) \\
\hline \multirow{2}{*}{ Hour worked } & $\leq 8$ hours & $162(48.5)$ & $172(51.5)$ & $334(87.7)$ \\
\hline & $>8$ hours & $40(85.1)$ & $7(14.9)$ & $47(12.3)$ \\
\hline \multirow{2}{*}{ Work shift } & Fixed & $174(50.4)$ & $171(49.6)$ & $345(90.5)$ \\
\hline & Rotating & $28(77.8)$ & $8(22.2)$ & $36(9.5)$ \\
\hline Department & Inpatient department & $152(49)$ & $158(51)$ & $310(81.4)$ \\
\hline \multirow{2}{*}{ Extra Responsibility } & Yes & $27(65.9)$ & $175(51.5)$ & $202(53)$ \\
\hline & No & $14(34.1)$ & $165(48.5)$ & $179(47)$ \\
\hline \multirow{2}{*}{ Role ambiguity } & Yes & $127(73.4)$ & $75(36.1)$ & $202(53)$ \\
\hline & No & $46(26.6)$ & $133(63.9)$ & $179(47)$ \\
\hline
\end{tabular}

\subsection{Factors Associated with Occupational Stress (Bivariate and Multivariate Analysis)}

To control for possible confounders multivariate logistic regression were used to test the association between independent variables and stress. All independent variables with p-value less than 0.25 in bivariate analysis were included in the multivariate analysis and $\mathrm{p}$ value less than 0.05 in multiple logistic regressions were considered as significant. The multivariate analysis indicated that Sex, marital status, role ambiguity and hour worked were significantly associated with occupational stress. The result revealed that female nurses were twice more likely to suffer from occupational stress than their male counterparts (AOR: 2.37, 95\% CI: 1.41, 3.97). Ever Married nurses were twice more likely to suffer from occupational stress than never married nurses (AOR: 2.49, 95\% CI: 1.35, 4.60). Nurse who had role ambiguity in their profession were three times more stressed than respondents who didn't face role ambiguity in their profession. (AOR: 3.01, 95\% CI: 1.79, 5.05) And nurses who were worked $>8 \mathrm{hr} /$ day were two times more stressed than from those who worked $\leq 8$ hours per days (AOR: 2.85, 95\% CI: 1.10, 7.36).(Table 8). 
Table 1. Results of bivariate and multivariate binary logistic regression of factors associated with occupational stress among nurses working in public hospitals of Arsi zone, Ethiopia, $2018(N=381)$.

\begin{tabular}{|c|c|c|c|c|c|}
\hline \multirow{2}{*}{ Variables } & \multirow{2}{*}{ Category } & \multicolumn{2}{|c|}{ Occupational stress } & \multirow{2}{*}{ COR $(95 \% \mathrm{CI})$} & \multirow{2}{*}{$\operatorname{AOR}(95 \% \mathrm{CI})$} \\
\hline & & Yes, N (\%) & Not, $\mathbf{N}(\%)$ & & \\
\hline \multirow{2}{*}{ Sex } & Male & $81(38.8)$ & $128(61.2)$ & 1.00 & 1.00 \\
\hline & Female & $121(70.3)$ & $51(29.7)$ & $3.74(2.44,5.76)^{*}$ & $2.37(1.41,3.97)^{* *}$ \\
\hline \multirow{3}{*}{ Age } & $<25$ years & $35(61.4)$ & $22(38.6)$ & $0.71(0.35,1.44)^{*}$ & $1.04(0.43,2.49)$ \\
\hline & 26-30 years & $109(45.4)$ & $131(54.6)$ & $0.37(0.22,0.63)^{*}$ & $0.53(0.27,1.04)$ \\
\hline & $>30$ years & $58(69)$ & $26(31)$ & 1.00 & 1.00 \\
\hline \multirow{2}{*}{ Marital status } & Never married & $71(35.7)$ & $128(64.3)$ & 1.00 & 1.00 \\
\hline & Ever Married & $131(72)$ & $51(28)$ & $4.63(2.99,7.15)^{*}$ & $2.49(1.35,4.60)^{* *}$ \\
\hline \multirow{2}{*}{ Children } & Yes & $88(71)$ & $114(44.4)$ & $3.06(1.93,4.85)^{*}$ & $0.75(0.38,1.45)$ \\
\hline & No & $36(29)$ & $143(55.6)$ & 1.00 & 1.00 \\
\hline \multirow{3}{*}{ Experience } & $<5$ years & $121(45.3)$ & $146(54.7)$ & 1.00 & 1.00 \\
\hline & $5-10$ years & $60(70.6)$ & $25(29.4)$ & $2.89(1.71,4.89)^{*}$ & $1.54(0.81,2.92)$ \\
\hline & $>10$ years & $21(72.4)$ & $8(27.6)$ & $3.16(1.35,7.40)^{*}$ & $0.53(0.18,1.58)$ \\
\hline \multirow[t]{2}{*}{ Role ambiguity } & Yes & $127(73.4)$ & $75(36.1)$ & $4.89(3.15,7.60)^{*}$ & $3.01(1.79,5.05)^{* *}$ \\
\hline & No & $46(26.6)$ & $133(63.9)$ & 1.00 & 1.00 \\
\hline \multirow{2}{*}{ Hour worked } & $<8$ hours & $162(48.5)$ & $172(51.5)$ & 1.00 & 1.00 \\
\hline & $>8$ hours & $40(85.1)$ & $7(14.9)$ & $6.06(2.64,13.93)^{*}$ & $2.85(1.10,7.36)^{* *}$ \\
\hline \multirow{2}{*}{ Work shift } & Fixed & $174(50.4)$ & $171(49.6)$ & $0.29(0.12,0.65)^{*}$ & $1.59(0.61,4.11)$ \\
\hline & Rotating & $28(77.8)$ & $8(22.2)$ & 1.00 & 1.00 \\
\hline \multirow{2}{*}{ Department } & Inpatient department & $152(49)$ & $158(51)$ & $0.40(0.23,0.70)$ & $0.39(0.20,0.75)$ \\
\hline & Outpatient department & $50(70.4)$ & $21(29.6)$ & 1.00 & 1.00 \\
\hline
\end{tabular}

$*=$ p-value $<0.25 * * \mathrm{P}$ value $<0.05 \mathrm{CI}=$ Confidence Interval, $\mathrm{COR}=$ Crude Odds Ratio, $\mathrm{AOR}=$ Adjusted odds Ratio.

\section{Discussion}

This study revealed that the prevalence of occupational stress among nurses were was 202 (53\%) with which was much higher than the studies conducted in Isfahan, Iran stated that the prevalence of stress was (34.9\%) [31]. and in Addis Ababa, Ethiopia the prevalence of occupational stress among nurses were (37.8\%) [14]. The discrepancy may be due to the tool difference and the sample size and the other possible explanation might be Isfahan, Iran had better implementation on regulation of health service delivery and occupational health and safety precautions.

The prevalence of occupational stress this study was much lower than the study conducted in Delhi, India the prevalence of stress among nurses were (87.4\%) [38]. The discrepancy may be due to sample size and tool different.

The prevalence of occupational stress this study lower than the study conducted in East Gojjam zone, Ethiopia the prevalence of stress among 178 nurses was (57.3\%) [5]. The discrepancy may be due to sample size and staffing/workload.

Expanded Nursing Stress Scale (ENSS) was measures the level of occupational stress among nurses in hospital units with eight subscales the descriptive analysis of the study indicated as first source of occupational stress for nurses among stress scale for this study was "workload". It was consistent with other studies conducted in Addis Ababa, East Gojjam Zone and Gombia [5, 35].

The possible explanation for this might be in most cases nurses were involved not only nursing activities but also other non-nursing activities like clerical work and the other reason might be due to the disparity of degree of shortage of nursing staff as it was reported in this finding.

The second source of occupational stress in this study was death and dying subscale. It was consistent with other studies $[17,35]$.

The possible explanation might be due to cultural, sympathy and empathy of the study participants as it is emotional issues regarding patient's death/dying.

The third source of occupational stress in this study was Uncertainty concerning treatment subscale. It was consistent with other study [5]. The possible explanation for this might be lack of adequate experience or skills to manage related the incidence, bio-medical legal issue and a sense of responsibility.

The fourth source of occupational stress in this study was problems with supervisors subscale It was consistent with other study [36]. The possible explanation for this might be Poor inter personal relationship and administration of nurses staff.

This study show significant association between sex of the respondents and occupational stress that was Female nurses were twice more likely to suffer from occupational stress than male nurses (AOR: 2.371, 95\% CI: 1.413, 3.976). This finding was consistent with other study this implies as female might be multiple role outside working place. But, This result was different from the study conducted in Arabia [34]. This difference may be due to difference in study participants; this study include all health professionals but the current study include only nurse professionals and the second reason might be socio- cultural different between countries.

Ever married nurses were twice more likely to suffer from 
occupational stress than never married (AOR: $2.494,95 \% \mathrm{CI}$ : $1.350,4.609)$. This finding was consistent with study done in karnataka India and Iran $[12,42]$. This might be implies Ever married greater social and economic expectation than never married. But, this finding was contradict with others studies. Due to tool different $(2,38)$. This result is not coinciding with the study conducted in Saudi [18]. which showed that workplace stress was not influenced by marital status the discrepancy might be cultural and tool used difference.

Nurse professional who had role ambiguity in their profession three times more likely to experience occupational stress than nurses who didn't face role ambiguity (AOR: 3.010, 95\% CI: 1.793, 5.054). This study result was consistent with the study conducted in Malaysia [43]. The first possible explanation might be lack of clarity on their job description regarding the nurse profession; the second possible explanation might be individual experiences inappropriate job expectation and can also occur when the individual is required to accomplish several different roles.

Current study revealed that no significant association between salary and stress level among nurse professional. But the study conducted in Germany and Austria among Physicians, Radiographers, Nurses and Medical Physicists working in radiotherapy showed that the greatest stress factors for nurses were low salary [34]. This discrepancy may be due to differences in tools used and previous study includes all health professionals in their study. Nurse professional who had worked more than $8 \mathrm{hrs}$. Per day twice more likely to experience occupational stress than nurses who had worked less than $\leq 8 \mathrm{hrs}$ per day. (AOR: $2.856,95 \%$ CI: $1.107,7.368)$ This study result was consistent with the study conducted in Saudi Arabia (79.4\%; $p=.001)$. [34]. The possible explanation might be shortage of staff and overtime. Which increases nurses workload. Besides this can have a significant effect on personal and social life. Even though it attracts pay enhancements but, can have a significantly effect on personal and social life.

This study could have the following limitation there might be response bias during data collection, however enough orientation was given regarding the objective of study and how to maintain confidentiality of the collected data in order to overcome bias.

\section{Conclusion}

The main finding of this study is that more than half of nurses' professional workings in Arsi zone public hospitals were occupationally stressful. Occupational stress was significantly associated with sex, marital status, working hours and role ambiguity. Whereas the measurement scale of occupational stress indicates that workload, death and dying, uncertain concerned treatment and problems with supervisor were the most stressful expanded nursing stress scale respective of their order. Therefore, Arsi zone public hospitals' emphasis needed on the occupational stress and associated factors among nurses to overcome this high level of occupational stress among nurses.

\section{Recommendations}

Based on the study findings we would like foreword the following recommendations.

To Oromia regional health bureau

a) Job description should be developed for all nurse staff per department unit to decrease role ambiguity regarding nurse professionals.

b) Oromia regional health Bureau collaborative with concerned stakeholders to design stress reduction program and strategy for tackling occupational stress among nurses.

To Arsi zone public hospitals

a) The hospital director, human resource managers and nurse administration collaborative with concerned staff shall provide induction and orientation during hiring of new nurse professionals.

b) Hospital administrative bodies should hire adequate nurse professional to decrease workload.

c) Training program should be organized for nurse supervisors in the field of administration this enables them to take planning measures on important stressors.

\section{To Researchers}

Finally, the investigators recommend further research to be undertaken on occupational stress among nurses using qualitative study for coping mechanism of occupational stress among nurses.

\section{Declaration}

Ethics approval and consent to participation.

Ethical clearance was obtained from the institutional Review Board (IRB) of Jimma University, institute of Health Science. Based on the cooperation letter second cooperation letter was also obtained from Arsi zone health office and given to hospitals to obtain consent and required information from all study subject. Written consent was obtained from each participant after thorough explanation of the purpose, potential risks and benefits and the procedures of the study. And also confidentiality was maintained as much as possible. Responses of respondents' were anonymous and data collectors were informed respondents that they have full right to discontinue or refuse to participate in the study.

\section{Consent for Publication}

I agree with the publication of this thesis.

\section{List of Abbreviations}

CI-Confidence interval

ENSS-Expanded Nursing Stress Scale 
HSDP-Health Sector Development Programme

IRB-Institutional Review Board

Km-Kilo Meter

NIOSH-National Institute for Occupational Safety and Health

NSS-Nursing stress scale

OR-Odd Ratio

PI-Principal investigator

SD-Standard Deviation

SPSS-Statistical Package of Social Sciences

\section{Acknowledgements}

I am grateful to my families and friends, who in one way or another helped me to accomplished this study in successful manner. In addition I would like to thank the study participants, data collectors and supervisors. The last but not the least thanks also go to Arsi Zone Health department and Arsi zone public hospitals for their cooperation for the availability of baseline information.

\section{References}

[1] National Institute for Occupational Safety and Health. Exposure to stress, Occupational Hazards in Hospitals. NIOSH. 2008. 20 p. Available from: https://mpra.ub.unimuenchen.de/50860/.

[2] Dagget T, Molla A, Belachew T. Job related stress among nurses working in Jimma Zone public hospitals, South West Ethiopia: a cross sectional study. BMC Nurs [Internet]. 2016; 1-10. Available from: http://dx.doi.org/10.1186/s12912-0160158-2.

[3] Sarafis P, Rousaki E, Tsounis A, Malliarou M, Lahana L, Bamidis P. The impact of occupational stress on nurses caring behaviors and their health related quality of life. BMC Nurs [Internet]. 2016; 1-9. Available from: http://dx.doi.org/10.1186/s12912-016-0178-y.

[4] Mccarthy VJC, Power S, Greiner BA. Perceived occupational stress in nurses working in. oxfordjournals [Internet]. 2018; 1 (October 2010): 1. Available from: https://academic.oup.com/occmed/articleabstract/60/8/604/1607289.

[5] Kassa DH, Afenigus AD, Meteku BT, Mengisitie BL, Telila BD. Assessment of Occupational Stress and Associated Factors Among Nurses in East Gojjam Zone Public Hospitals Northwest Ethiopia, 2016. Sci Publ Gr [Internet]. 2017; 6 (2): 43-8. Available from: http://www.sciencepublishinggroup.com/j/cmr.

[6] Hse SE. Health and Safety Executive Annual Statistics Report [Internet]. 2010.2 Available from: http://www.hse.gov.uk/statistics/index.htm.

[7] Executive S. Work-related Stress, Depression or Anxiety Statistics in Great Britain 2017 [Internet]. 2017. Available from: www.hse.gov.uk/statistics/.

[8] Eleni M, Fotini A, Maria M. Research in occupational stress among nursing staff-a comparative study in capital and regional hospitals. Hell J Nurs Sci [Internet]. 2008 [cited 2013
Oct 31]; $3 \quad$ (3): $\quad$ 79-84.Availablefrom: http://magazine.enne.gr/wpcontent/uploads/2010/11/tomos3te fxos3_aggliko.

[9] Alhajjar BI. Occupational stress among hospital nurses in Gaza-Palestine. 2013ci Publ Gr [Internet]. 2013; 6 (2): 2-8. Available from: http://www.sciencepublishinggroup.com.

[10] A OO, Osamudiamen OS, Ojo AA. Occupational stress management among nurses in selected hospital in Benin city, Edo state, Nigeria. Pelagia Res Libr [Internet]. 2013; 3 (1): 473-81. Available from: www.pelagiaresearchlibrary.com Pelagia.

[11] Khamisa N, Peltzer K, Oldenburg B. Burnout in Relation to Specific Contributing Factors and Health Outcomes among Nurses: A Systematic Review. Int J Environ Res Public Health [Internet]. 2013; 10: 2214-40. Available from: www.mdpi.com/journal/ijerph.

[12] Jose T, Bhat SM. A descriptive study on stress and coping of nurses working in selected hospitals of Udupi and Mangalore districts Karnataka,. J Nurs Heal Sci [Internet]. 2013; 3 (1): 10-8. Available from: www.iosrjournals.org.

[13] Moustaka E. Sources and effects of Work-related stress in nursing. Heal Sci J [Internet]. 2010; 4 (4 (2010)): 210-6. Available from: www.hsj.gr.

[14] Zewdu S, Alemu AWork-Related Stress and Associated Factors Among Nurses Working in Public Hospitals of Addis Ababa, Ethiopia: A. ResearchGate [Internet]. 2014; 62 (July 2016): 326-31. Available from: https://www.researchgate.net/publication/264640309\%0A.

[15] Sousa F, Maria M, Cabugueira M, Teresa E, Carolino A. Psycho-social risks at work: stress and coping strategies in oncology nurses. 2013; 21 (6): 1282-9.

[16] Sibbald B, Bojke C, Gravelle H. Primary care National survey of job satisfaction and retirement intentions among general practitioners in England. 2003; 326 (January): 1-4.

[17] Kyreaa a. causes of stress among nurses in the greater accra region. int j res soc sci [internet]. 2014; 3 (8): 3-4. available from: www.ijsk.org/ijrss.

[18] Mohite N, Shinde M, Gulavani A. Occupational Stress among Nurses Working At Selected Tertiary Care Hospitals. Int J Sci Res [Internet]. 2014; 3 (6): 999-1005. Available from: www.ijsr.net.

[19] Asegid A, Belachew T, Yimam E. Factors Influencing Job Satisfaction and Anticipated Turnover among Nurses in Sidama Zone Public Health Facilities, South Ethiopia. Nursing Research and Practice. 2014; 2014: 26.

[20] Dr. Janice Rider Ellis rn phd anef ms. Celia Love Hart. 344Nursing in Today's World, 10 Edition-.

[21] Health FDR of EM of, 2014/15 H. Health sector developmental program [Internet]. 2014. Available from: http:www.google.com.

[22] Chen X, Tan X, Li L, Al ET. Health Problem and Occupational Stress among Chinese Doctors. 2013; 2013 (March): 1-6.

[23] Canadian Centre for Occupational Health and Safety. 2012; http://www.tbs-sct.gc.ca/est-pre/20112012/me-bpd/toc-tdmeng.asp. 
[24] Roland G. International journal of Emerging Trends in Science and Technology Author. 2014; (2006): 463-76.

[25] Aburuz ME. a comparative study about the impact of stress on job satisfaction between jordanian and saudi nurses. 2014; 10 (17): 162-72.

[26] Organzation international labour. S tr ess [Internet]. 2016. 2-6 p. Available from: www.ifrro.org.

[27] Cox SC, Rial-González AGE, Institute. Research on Workrelated Stress [Internet]. 2000. 32-36 p. Available from: http://europa.eu.int.

[28] Yao A. Relationship Between Occupational Stress and Job Satisfaction: An Empirical Study in Malaysia. Rom Econ J. 2009; 34 (34): 3-29.

[29] Stavroula leka, protecting workers $\mathrm{a}^{\mathrm{tm}}$ work world health. who libr cat data leka,. 2012; 3 (3): 5-9.

[30] Cox SC, Rial-González age, Institute. Research on Workrelated Stress. Eur Agency Saf Heal Work [Internet]. 2000; 3: 32-6. Available from: http://europa.eu.int.

[31] Mosadeghrad AM. Occupational Stress and Turnover Intention: Implications for Nursing Management. Int $\mathrm{J}$ Heal Policy Manag [Internet]. 2013; 1 (2): 169-76. Available from: http://ijhpm.com.

[32] Gulavani A, Shinde M. Occupational Stress and Job Satisfaction among Nurses. Int J Sci Res [Internet]. 2014; 3 (4): 733-40. Available from: www.ijsr.net.

[33] Alhajjar BI. Occupational stress among hospital nurses in Gaza-Palestine. 2013; 140-5.

[34] Salam A, Abu-helalah M, Jorissen SL, Qarni a al. job stress and job satisfaction among health care professionals Abuelgasim Mansour. Eur Sci J [Internet]. 2014; 10 (32): 156-73. Available from: www.European Scientific Journal.com

[35] State G, Danjin M. work related stress among hospital- based nurses in sub-urban settings in international journal of pharmacology research sub-urban settings in gombe state, nigeria. ResearchGate [Internet]. 2017; 6 (January 2016): 27 2. Available from: www.ijprjournal.org.

[36] Mohamedkheir RA, Amara ZM, Balla SA. Occupational Stress Among Nurses Working in Intensive Care Units in Public Hospitals of Khartoum State, Sudan 2016. Am J Heal Res [Internet]. 2016; 4 (6): 166-71. Available from: http://www.sciencepublishinggroup.com/j/ajhr.

[37] Makhaita HM Al, Sabra AA, Hafez AS. O riginal Article Predictors of work - related stress among nurses working in primary and secondary health care levels in Dammam, Eastern Saudi Arabia. 2014; 21 (2): 79-84.

[38] Bhatia N, Kishore J, Anand T, Jiloha RC. Occupational Stress Amongst Nurses from Two Tertiary Care Hospitals in Delhi Occupational Stress Amongst Nurses from Two Tertiary Care Hospitals in Delhi. researchgate [Internet]. 2010; 733-734 (May 2014). Available from: https://www.researchgate.net/publication/232084693\%0AOcc upational.

[39] Ebrahim M, El A, Hafez SK. Effect of Job Related Stressors on Nurses $\hat{a} €^{\mathrm{TM}}$ Job Satisfaction in El - Shatby Maternity University Hospital, Alexandria, Egypt. 2014; 32 (2): 1-20.

[40] French S, Lenton R, Walters V, Eyles JAn emprical evaluation of an expanded nursing stress scale. Nurs Meas [Internet]. 2000; 8 (2): 162-76. Available from: www.MNSS.com.

[41] FeAzman Ismail, Amy Yao, Elizabeth Yeo KFeatures s, intelligence $e$, in $s$, institutions $p$, higher of. occupational stress features, emotional intelligence and job satisfaction: an empirical study in private institutions of higher en el trabajo. sci e-journal manag sci [internet]. 2010; 16 (4): 5-33. available from: www.revistanegotium.org.

[42] Mosadeghrad AM. Occupational Stress and Turnover Intention: Implications for Nursing Management. 2013; 1 (2): 169-76.

[43] Binti J, Yunus M, Jumaat A, Mahajar B, Business C, No CO, et al. Work Overload, Role Ambiguity and Role Boundary and its Effect on Burnout among Nurses of Public Hospitals in Malaysia. Int J Res Humanit Soc Stud. 2015; 2 (10): 18-25. 